\title{
Introduction
}

\section{Moving forward, kicking back: The animal turn}

\author{
Cary Wolfe \\ Department of English, Rice University, Texas.
}

postmedieval: a journal of medieval cultural studies (2011) 2, 1-12.

doi:10.1057/pmed.2010.46

Several years ago, when the University of Minnesota Press approached me about the possibility of editing a series, I had free rein to think about what its rubric would be. At the time, one of the areas with which I had been occupied for a number of years was what is now called 'animal studies,' though my interest in the topic reached back to my years as an animal rights activist in North Carolina in the mid-to-late-1980s. I've discussed the vagaries of this label in more detail elsewhere (Wolfe, 2010), but call it what you will - 'animal studies,' 'animality studies,' 'human-animal studies' - there was no 'animal studies' when I published my first essay in that emerging field in 1995: a co-authored piece with Jonathan Elmer on Jonathan Demme's The Silence of the Lambs (1992), and the intense crossings of species, sexuality, and gender that swarm at every level of that remarkable film. A few pieces of scholarly work devoted to 'the animal question' existed at the time; two of the best known were probably Harriet Ritvo's The Animal Estate (1989), a historical study of the parallels between selective breeding practices and class structures in Victorian England, and Carol Adams's The Sexual Politics of Meat (1990), a cross-mapping of the representational strategies that analogize the bodies of animals and women as objects of consumption in twentieth-century Western culture. You could find scattered engagements, here and there, in contemporary continental theory and philosophy, such as Bataille's Theory of Religion (1992), Deleuze and Guattari's riffing on 'becoming-animal' in A Thousand Plateaus (1987), or Derrida's famous 
analysis of Heidegger and the question of animal ontology in Of Spirit (1991). And though the founding philosophical texts of the animal rights movement had been around for a while - Peter Singer's Animal Liberation (1975) and Tom Regan's less famous but equally accomplished The Case for Animal Rights (1985) - little if any impact had been made by those texts on the day-to-day work of scholars in cultural studies. In those days, plenty of sub-species of cultural studies existed, but animal studies wasn't one of them; and scholarly talk about 'the animal' or animality almost always was treated as a vehicle or symptom for some other, deeper problematic: often race or gender, sometimes class or nationality (as in Balibar and Wallerstein's still vital 1991 collection, Race, Nation, Class).

Things have changed; as Peter Travis observes in this issue, 'In the past decade, animal studies has exploded onto the scene, with articles, books, and conferences expanding the field's vocabulary and posing theoretical questions at an astonishing rate.' In fact, they have changed so much that when Minnesota approached me about editing a series, the question wasn't so much could I do an 'animal studies' series, but rather could I avoid doing one. For reasons that this issue of postmedieval helps to make clear, I chose instead to build the series around the idea of posthumanism: not posthumanism in the sense of that which is posthuman (that which transcends or escapes the bounds of the human) but rather in the sense of that which is posthumanist (that which thinks fundamental social and cultural questions outside of or at least askance to the humanism that we have inherited in our philosophical habits, political institutions, cultural and religious conventions, and much else). One of the wonderful things about the sort of scholarship represented here is that it helps to make clear that the 'post' of posthumanism doesn't designate a simple linear, chronological concept - a 'that which comes after,' in which posthumanism is the most recent academic fashion or flavor of the month - but rather, it marks a complex and multi-dimensional relationship of temporality and conceptuality that might best be thought on the model of topology (as Michel Serres might put it), in which the historically distant periods of the Middle Ages and postmodernity may actually have more in common with each other than either period does with the defining (for our culture) era of humanism that they bookend.

Similarly, the cross-talk between the essays collected here and the inaugural issue of postmedieval on the post/human, to which Katherine Hayles contributed a Response, helps to make it clear that the question of the animal, and animal studies generally, is best approached in concert and conversation with the larger problematic of posthumanism, whether we understand it in terms of hybridity and actor-network theories (with Latour (2007) and Haraway, (2007)), the paradoxical logics of the parasite, the third, and quasi-objects (with Serres (2007) and Luhmann (1995)), theories of technogenesis and originary technicity (with Leroi-Gourhan (1993), Stiegler (1998), and certain strains of 
Derrida's work (1998)), or in other ways. Once we understand that 'the human' and 'the animal' are relics of a philosophical humanism that flattens the actual complexity and multidimensionality of what are, in fact, many different ways of being in the world that are shared in myriad particular ways across species lines, then the question of the animal - and of the animality of the human cannot help but open onto fundamental issues that are best thought not as problems of distinct and discreet ontological substances, but rather in terms of processes, dynamics and relations - what Donna Haraway (2007) winningly calls 'contact zones' between human and non-human life forms and the environments, technologies, prostheses, and practices in which they are embedded as beings both acting and acted upon. Most decisive here, of course, is the growing understanding that language, tool use, and tool-making - and indeed cultural behaviors generally - are not limited to homo sapiens alone, or even to small branches of the animal kingdom (such as Great Apes). The processes and material substrates that gave rise to the complex phenomenologies and behaviors that humanism thinks of as the sole domain of the human are, we now know, found in large neighborhoods of the animal world. This doesn't mean that humans and animals are 'the same'; rather, it simply means that the human/animal distinction is far too blunt a conceptual instrument to be of much use.

Scarcely a week goes by in which major media outlets don't announce a growing consensus among scientists about the remarkable mental and psychological complexity of other forms of life. To take a ready-to-hand example, in a New York Times article on June 27, 2010 (occasioned by the meeting of the International Whaling Commission to discuss lifting the 24-year ban on commercial whaling), one scientist observes that when you compare levels of self-awareness, sociality, the importance of culture, cetaceans come out on most of these measures in the gap between chimps and humans. They fit the philosophical definition of personhood' (Angier, 2010). In fact - and this is bound to strike even some fellow travelers of animal studies as news - among some types of whales, we find what amounts to a kind of ethnicity or cultural identity, which they express through specific dialects that, remarkably enough, become exaggerated when a particular group is in proximity to another clan. 'It's like if you're Irish and you run across someone who is Scottish or Welsh,' the scientist analogizes. 'You'll speak with an even stronger Irish accent to make it really clear whose group you belong to' (Angier, 2010). I mention the example of cetaceans for a couple of reasons. First, it reminds us of the terrestrialist bias that still obtains in animal studies, as if dogs, cats, horses, and farm animals were adequate stand-ins for the vastness and diversity of animal life on the planet. And this in turn points to just how inadequate the moniker of 'animal studies' really is: not just because the other-worldliness of some forms of sea life helps us see that there is no 'the animal' - cetaceans are 'like intelligent aliens living among us,' another scientist observes (Angier, 2010) - but also 
because it helps to underscore how the other end of the 'animal studies' label, the 'studies' end, smuggles in certain normative notions of the 'cultural studies' on which it is modeled. Those notions that are not just interrogated (to use that old 1990s locution) but submarined (to use one more appropriate to this context) once we start taking seriously non-human culture, non-human ethnicity, non-human tool use, non-human language, and so on. And in this light, one can readily see why the point cuts both ways: posthumanism, with its central concerns such as technicity, prostheticity, actor-networks, and distributed cognition, has just as much to learn from animal studies as animal studies does from posthumanism.

When the Times article I have been referencing observes of the practice of whaling that 'maybe we shouldn't talk about what we're harvesting or harpooning, but whom,' we are pointed in the direction of a distinctive feature and challenge of animal studies, one that separates it (though neither cleanly nor definitively) from fellow travelers in the posthumanism fold such as the vital materialism we find in Jane Bennett's work (2010) or the Actor-Network Theory of Latour (2007). To put a somewhat finer point on it, it is one thing to describe the network of relations between species, ecosystems, political structures, legal strictures, histories of extirpations (both human and animal) and technologies that converge, for example, in the overpopulation of the White-Tailed Deer (Odocoileus virginianus) in much of North America. It is another thing to decide whether or not it is permissible to kill them when we know more than ever about the complexities and texture of their phenomenological lives and their capacity to experience suffering (both physical and psychological) in ways not that distant from our own. And more pointed still: why would we countenance such a solution to the problem and not recommend it as a way to deal with the overpopulation of our own species, whose effects on the planet are exponentially more destructive? To answer 'because we're humans' is to take for granted the very ontological difference between human and non-human animals that has been decisively undermined over the past three decades and more. As animal rights philosophy pointed out long ago, it is specieism pure and simple: the assumption that membership in a species (rather than the possession of the morally relevant characteristics we have been discussing, wherever we find them) is what determines standing, which is no better than the racism or sexism on which the term analogizes. Animal studies, in other words, bears a distinctive relation to questions of ethics that forces us to parse the various components of an actor-network or an assemblage in a rather different way, recognizing that some members of a network and not others are bound by a shared finitude as fellow creatures who live and die, who care about what happens to them and to those they hold dear.

Sarah Kay's essay reminds us that the question of ethics in relation to nonhuman animals is anything but a dry 'if $\mathrm{P}$ then $\mathrm{Q}$ ' propositional derivation of what just treatment of our fellow creatures might look like. Instead, 
it involves affect, the body, touch and proprioception: in short, the event of bodies encountering bodies, flesh on flesh. In this light, one might suggest that there is something fundamentally lost - barren, even - in the contemporary experience of reading as we find its apotheosis in the Kindle and similar devices, whose ideal (or fantasy) would seem to be to largely bypass this dimension of bodily encounter. The fact that medieval texts are written on animal skins that often bear the material marks of their origins (veins, curves and curled edges, spinal imprints, and even holes) means that the surface upon which the text is inscribed 'insinuates a disturbing presence in the field of symbolization that is not itself symbolized.' Against this background, we can amplify Kay's question: 'to what extent do texts written on parchment give readers the sense of having an animal skin,' of being a fellow creature? The process that Kay has in mind seems to me almost the opposite of what we find in contemporary body art, in which the human being's skin is reminded of its animality by being punctured and incised, bloodied and scabbed, but usually for the purpose of inscribing and assuming a Symbolic mandate of some kind (as in the stereotypical examples of 'Mom' or the proper name of a lover or, quite often, an icon of some kind). The fundamental psychic economy of much body art would seem to be good old Enlightenment $S$ and $\mathrm{M}$, in other words, even if the mandate being assumed is that of a particular subculture, with its secret codes and symbols. But Kay has in mind something different. Here, the book as the site of Symbolic mandate and legacy is haunted - 'spectralized,' as Derrida (1994) would put it - by a finitude, a 'will have been,' that we, as animals, share with the creatures whose skin before us testifies to their passing - and eventually to ours. And yet there is a violence here that flows overwhelmingly in one direction, for as Kay notes, the production of parchment was part and parcel of the farming of sheep for all sorts of purposes, not least of all, for food.

In texts such as the medieval fabliau of The Butcher of Abbeville, the standard stereotypes, fables, and proverbs in which the supposedly 'allegoryaddicted' Middle Ages make ample use of animal figures and tropes are reversed, or we are brought into uncomfortable proximity with the 'surface' of the text (versus its 'deep' meaning) in several senses. As animal studies scholar Ron Broglio points out in his book On the Surface, traditionally, non-human animals (because of their supposed lack of reason, feeling, psychological depth, and so on) 'are said to live on the surface of things', in a world of 'fleeting appearances, mere shadows lacking the substantiality found in the "depth" of human interiority' (Broglio, 2011, n.p.). But the surface can instead be a site of transvaluation, an unpredictable zone of contact that opens us, in a sensory and bodily event, to other ways of being in the world. To be sure, such a site is neither sanguine nor predictable. This is not a petting zoo. As Kay writes of the second text she analyzes, Ysengrimus, 'The very legibility of skin, given how mobile and transferable it is, militates against any fixing of categories. The only existence in these texts is that of undulating, circulating skin - a surface 
1 But see David Wills's revisitation of Levinas and the Face in Wills (2008), Chapter Two. that ultimately is not distinguishable from the material support of the text itself.' In any case, reading is not a hermeneutic of 'renouncing skin for some supposedly deeper meaning, or in stripping the text back to the "meat," but rather in enjoying the potential mobility and contingency of skins that have been furnished for this purpose, and which the reader too can play with assuming.' The text's emphasis on skins and surfaces and their shifting points of contact means that 'the reader's self, grounded in the original Skin-Ego, is constantly at risk of being modeled on that of the beasts. The very legibility of skin, given how mobile and transferable it is, militates against any fixing of categories. The only existence in these texts is that of undulating, circulating skin - a surface that ultimately is not distinguishable from the material support of the text itself.'

At the same time, however, the regime of reading - and even more pointedly, perhaps, than the domain of 'the Name,' as Deleuze and Guattari put it (Deleuze and Guattari, 1987, 26-28) - always threatens to reinstall the Symbolic mandate of the human. The 'human' is he - and it must be 'he' by this logic who reads, he who names and has a name as a means of managing or disavowing 'becoming' in the more radical sense that Kay, following Deleuze and Guattari, imagines. Reading and the Name always threaten to reinscribe what they call the fundamental grid of 'facialization' in which the 'face' refers not to a body part, much less a human one, but to a schema that localizes and tames the unruliness of desire, affect, and becoming in the form of fixity and identity (1987, 168-171). The point bears emphasizing because the locus of the Face, ever since Levinas, has been an important one for animal studies in thinking the ethical encounter between the human and the animal. Derrida's anatomy of the 'visor effect' in Specters of Marx (1994), the famous moment of being looked at by his cat in The Animal that Therefore I Am (2008, 11), and Deleuze and Guattari's rethinking of the Face via 'facialization' are attempts to move beyond the humanism that anchors Levinas's model of the encounter. ${ }^{1}$ 'The fact of turning an animal skin into a manuscript "facializes" it,' Kay writes, and 'this legibility of the face overlays and arrests the drift into multiplicity of the undulating body.' Reading, that most supremely human of activities, is thus always haunted by that which the regime of sense and the Symbolic excludes - 'sacrifices,' as Derrida would put it (Derrida, 2008, 42). We thus find, according to Kay, 'a short-circuiting between the usually distinct levels of text and book which might entirely escape conscious perception, but which nevertheless obtrudes on the reader. The effect of this short-circuiting is uncanny in the sense that it insinuates a disturbance in the field of symbolization, even if this disturbance is not itself symbolized.' Though Kay doesn't say so, we find here the Derridean logic of the prosthesis and the supplement at work - a logic that will be important, as we will see, to both Susan Crane's and Gary Lim's analysis of knight and warhorse. For the very thing that makes the 'human' what it is, that which secures its privilege as such - reading, the Word, 
the Name - is the very thing that bodies forth the radical dependence on and openness to all that the human is not: not just the archive and semiotic code in all its exteriority and technicity, but also its very material support (Derrida, 1998).

Peter Travis is concerned with the site of reading as well - and specifically with the work of allegory - as a site of violence. As Gorden Teskey puts it, 'The more powerful the allegory, the more openly violent the moments in which the materials of narrative are shown being actively subdued for the purpose of raising a structure of meaning.' And allegories and fables in the Middle Ages, Travis writes, in turn 'helped to valorize conservative cultural principles by policing the boundaries between the sought-for humanist ideal - that is, the well-educated and well-disciplined male subject - over against such "others" as women, peasants, children, and animals.' Yet Travis, like Kay, is concerned not so much with depth as with surface - in this case, the surface of Aesop's body itself, marked as it is by three striking features: that it is a slave body, that it is physically deformed, and that it is physically incapable of speech well into adulthood. Here too, in other words, we are dealing with 'skin.' And in this case, Aesop's 'transgressive body, thought to be more animal than human, undoes 'the "either/or" logic of all categories that neatly bifurcate the animal corpus from the human.' The same is true of Aesop's relation to speech - that attribute which is taken to mark 'the insuperable line,' as Jeremy Bentham once famously put it, between humans and animals (Derrida, 2008, 27). Aesop's movement from muteness to eloquence and artistry dramatizes the fragility of such associations and the ontological presumptions they support, only to further subvert them by giving speech back to animals in the fables themselves, but only (ironically enough) in the services of their subjugation as mere allegorical vehicles. In the figure of Aesop's body and its history more than in the fables themselves, Travis finds a rejoinder to the suggestion of Stephen Jay Gould and others that all representations and conceptualizations of animals are unavoidably anthropocentric - a rejoinder that he glosses by way of Derrida's famous rejection of the idea of 'the Animal' (Derrida, 2008, 32-34). 'Rather than l'Animal, we must speak only in the plural of les animaux,' Travis writes. 'From les animaux, however, Derrida moves immediately into his celebrated neologism l'animot: here, not only singular and plural ... but animals and language (les mots) are melded into a chiastic, catachrestic, and countervailing sign.' And this enables us to see 'that Aesop actually anticipates l'animots. He is plural, embodying the shapes of many animals, yet singular. His inscrutable stutterings may be traces of an alternate language his masters cannot comprehend.' Indeed, in his selection of the tongues of swine and oxen for a series of dinners at the house of his master, Xanthus, Aesop emerges as an ancestor not just to the figure of homo alalus as discussed by Agamben (2004) and others, but even more pointedly to Hannibal Lecter in The Silence of the Lambs, undoing from the inside the very conceptual architecture and ontological coordinates of his 
supposedly enlightened society. As Travis puts it, 'Hannibal's and Aesop's feasts of tongues are extraordinary philosophical meals, both interrogating, from discretely distinct critical positions, the carnophallogocentric foundations of Western society.' While Lecter eats the tongue out of a nurse's mouth without raising his pulse, and declares his favorite meal to be the liver of a human victim with a fine Chianti, Aesop 'does not partake of the lingual feast he serves his philosophical masters,' thus 'avoiding, perhaps just barely, the equation of the carnivore with the cannibal.' Of course, one might well conclude that Aesop is in no position to pursue to its ultimate conclusion the logic that he has set loose in serving tongues to Xanthus's guests. Like Lecter, he is a master 'reader'; but given his station, he can walk the walk, you might say, but must stop short of talking the talk.

To raise the question of Aesop's slavery and station is to raise the question not just of ethics but of politics - a question that bears more directly on the essays of Lim and Crane. Lim asserts that 'Bevis of Hampton suggests that medieval imaginations welcomed the possibility of admitting animal others into these reciprocal relationships. Ultimately, the romance invites us to expand our concepts of fealty and vassalage beyond species lines.' What we find here is a sort of proto-biopolitics in which both human and non-human animals are articulated with each other in complex and quite differentiated ways as part of a larger political project. This is a particularly welcome development in medieval scholarship, because the conversation between biopolitics and animal studies two quite separate intellectual genealogies, the former largely European, the latter largely North American - has just recently begun to gain some momentum. As is well known, biopolitical thought traces its immediate genealogy to Michel Foucault's later work. Foucault argues in The History of Sexuality that, 'for millennia, man remained what he was for Aristotle: a living animal with the additional capacity for a political existence; modern man is an animal whose politics places his existence as a living being in question' (Foucault, 1978, 143). Moreover, as Foucault famously defines biopolitics, it 'is the power to make live. Sovereignty took life and let live. And now we have the emergence of a power that I would call the power of regularization, and it, in contrast, consists in making live and letting die' (Foucault, 2003, 247). (Foucault's main examples are medicine, madness, and the rise of the various 'health' professions under the broader regime of 'governmentality' and its specifically modern techniques of managing, directing, and enhancing the lives of populations via hygiene, population sciences, food sciences and so on, the better to extend and consolidate political power.)

It's worth reminding ourselves of a thumbnail definition of biopolitics in its Foucauldian rendition because it enables us to differentiate between the particular dispositifs at work that connect humans, animals, technologies, and disciplines and the question of the particular type of political structure that they serve - be it sovereignty in the Middle Ages and Renaissance, or 
governmentality in the modern period. Or to put it more directly still, we need to distinguish the fact of biopower from the biopolitical per se. Such articulations of bodies with the practices and institutions that configure the social order are often quite specific with regard to the type of animal in question. As Lim points out, certain animals - in particular what we might designate as The Three H's (horses, hounds, and hawks) - achieved rarified status and were especially prized gifting currency among the elite. But what makes Lim's examples resonate with Foucault's concepts of biopower is that they capture the essential ambivalence and dynamic instability that, for Foucault, inheres in the political gambit of seizing upon the forces and potentialities of bodies for political purposes. As Maurizio Lazzarato puts it, 'power passes through the body, not because power is "omnipotent and omniscient" but because every force is a power of the body. Power comes from below; the forces that constitute it are multiple and heterogeneous. What we call power is an integration, a coordination and determination of the relations between a multiplicity of forces' (Lazzarato, 2002, 105). Using animal gifts to secure the feudal order, as it turns out, is far from a unilateral, unproblematic exploitation of an always already abject animal - far from it. As Lim writes of Bevis's prized warhorse, 'when Arondel's body cannot be easily circulated - because it is an independent, resistant force and because Bevis himself relates to the horse as a feudal subject rather than an exchangeable object - the romance's feudal norms are challenged.' It is important to note that this challenge 'from below' comes not just from Bevis but also from his horse - it comes from 'below below,' if you like. 'Arondel is thus depicted as a gift whose value operates in a paradoxical manner,' Lim concludes. 'While Arondel is valued because he is a powerful, swift horse, his power must be entirely mastered for him to be valuable as an alliance-building gift as his submission is required for him to be a freely exchangeable object.'

While the relations at work here are not, strictly speaking in Foucault's sense, 'biopolitical' - for one thing, such articulations are highly individualizing rather than obeying the 'massifying' logic that will be characteristic of biopolitics proper in a period of governmentality (Foucault, 2003, 243) - they nevertheless show a key component of Foucault's thinking of politics in terms of biopower. The relations at work here aren't only political or strategic, and they demonstrate how, for Foucault, the political cannot be cleanly cordoned off from the ethical. As Lazzarato observes, 'Foucault interprets the introduction of "life into history" constructively because it presents the opportunity to propose a new ontology, one that begins with the body and its potential, that regards the "political subject as an ethical one" against the prevailing tradition of Western thought which understands it as a "subject of law"' (Lazzarato, 2002, 100). In this light, we can understand that Bevis's profound bond with Arondel isn't merely sentimental or self-serving, and we can further appreciate the full resonance of the fact that Bevis chooses to leave England rather than turn 
2 For a useful critical overview of the similarities and differences
Arondel over to the gallows after the king's son attempts to steal him and Arondel kicks him to death.

Lim's exploration of the 'contact zones' in which 'individuals of different species interact by ceding power and sharing control in order to inhabit new and surprising subjectivities' is developed in some detail in Susan Crane's fascinating anatomy of the medieval 'knyght ... on horsebacke.' In an observation resonant for Lim's discussion of Bevis of Hampton, Crane notes that 'Sometimes the assemblage of armed knight and horse is presented as a mechanism coordinating multiple bodies and technologies, and sometimes instead as a partnership that attributes courage, nobility, and initiative to both knight and horse.' Against the Foucauldian background we have been developing, we are in a position to see the payoffs - and the risks - of having access to both sets of resources. As Crane makes clear, understanding medieval chivalry requires a reading that is both technological and symbolic, both political and (if you like) ontological. And while our humanist habits might take these as rough opposites, the posthumanist perspective that understanding chivalry requires finds them deeply enfolded with each other. Crane writes,

Oscillating along the lines of difference between a combat mechanism and a conscious partnership, the medieval conception of knight and horse embraces a fundamental instability ... The intermingling of these opposed conceptions expands chivalric self-definition in two directions that may look contradictory, but even the apparent contradiction reinforces chivalry's special importance. Mechanization and living relationship could each be suspect in the absence of the other. The technological aspect of chivalry threatens the knight with objectification as just so much equipment, but the conscious component in the relationship of knight and horse resists objectification. Conversely, cross-species contact threatens the knight with bestial abasement, but the technologies of breeding, training, and arming the warhorse counterbalance mere animality with their prestigious elevations.

What we find here is an essentially prosthetic logic that is bound to deconstruct our attempt to maintain not just the purity of the distinction between knight and horse, man and beast, but of the very idea of the human itself. To be sure, the knight's sword is a prosthetic enhancement of the arm; his armor, of the skin. But as contemporary thinkers such as Bernard Stiegler (1998), Jacques Derrida (1998), and David Wills (1995) have shown, the logic of the prosthetic goes far deeper than that and, in Stiegler's work in particular, it has an anthropological and evolutionary cast. ${ }^{2}$ As Stiegler puts it, following Andre Leroi-Gourhan's work on the co-evolution of tool use and corticalization in humans, "The evolution of the "prosthesis," not itself living, by which the human is nonetheless defined as a living being, constitutes the reality of the 
human's evolution, as if, with it, the history of life were to continue by means other than life: this is the paradox of a living being characterized in its forms of life by the nonliving - or by the traces that its life leaves in the nonliving' (Stiegler, 1998, 50). What this means - and the points of direct contact with his former teacher Derrida's logic of the supplement are all the more clear at this juncture - is that the idea of the 'human' as fundamentally an interiority that is ontologically distinct from its outside 'is inverted in this movement ... Interior and exterior are consequently constituted in a movement that invents both one and the other: a moment in which they invent each other respectively, as if there were a technological maieutic of what is called humanity. The interior and the exterior are the same thing, the inside is the outside, since man (the interior) is essentially defined by the tool (the exterior)' (Stiegler, 1998, 142).

On the one hand, the knight was quite distinct from the masses of humanity, of course, and elite technologies to which only he and his peers had access enmeshed him 'in an assemblage that wields immense social and military authority.' He is a singularity. On the other hand, we find bodied forth in the practice of mounted combat and the training necessary to participate in it the truth of the human condition itself: a product of technogenesis, disciplinary and discursive practices, and articulations of the body in consort with external forces (and other bodies, including animal ones) that fundamentally rewire the wetware of homo sapiens itself (and the bodies of his opponents, the knight hopes!). Thus, what looks like and in many respects was - the very height of human power and mastery turns out to stage interdependency, hybridity, and relationality as the source of both power and the ceding that power requires. The knight becomes the apotheosis of that thing called 'human' not because of his transcendence of the animal and the technical, but precisely because of his intrication with them. To become what 'he' is, he has to become a 'they,' an assemblage made up of components both human and non-human, living and technical. The knight on horseback is thus, in many senses, a moving target. As Crane puts it, most profoundly of all, 'The knight's self-definition through chivalric practice involves technique and specialized training, but also a venturing into an enigma, a reaching out beyond the human into interspecies relationship.' And in this light, in this 'contact zone,' the enigma that we encounter when we put animals to our purposes perhaps makes our prosthetic entanglements in technicity seem a rather tidy affair by comparison. Because after all, animals can kick back.

\section{References}

Adams, C. 1990. The Sexual Politics of Meat: A Feminist-Vegetarian Critical Theory. London: Continuum.

Agamben, G. 2004. The Open: Man and Animal, trans. K. Attell. Stanford, CA: Stanford University Press. between Stiegler's position, Derrida's, and Wills's own, see Wills (2006). 
Angier, N. 2010. Save a Whale, Save a Soul, Goes the Cry. The New York Times 27 June: WK 3.

Balibar, E. and I. Wallerstein. 1991. Race, Nation, Class: Ambiguous Identities, trans. C. Turner. London: Verso.

Bataille, G. 1992. Theory of Religion, trans. R. Hurley. Cambridge, UK: Zone Books.

Bennett, J. 2010. Vibrant Matter: A Political Ecology of Things. Durham, NC: Duke University Press.

Broglio, R. 2011. (forthcoming) On the Surface: Thinking with Animals and Art. Minneapolis, MN: University of Minnesota Press.

Deleuze, G. and F. Guattari. 1987. A Thousand Plateaus: Capitalism and Schizophrenia, trans. B. Massumi. Minneapolis, MN: University of Minnesota Press.

Demme, J., dir. 1992. The Silence of the Lambs. Orion Films.

Derrida, J. 1991. Of Spirit: Heidegger and The Question, trans. G. Bennington and R. Bowlby. Chicago, IL: University of Chicago Press.

Derrida, J. 1994. Specters of Marx, trans. P. Kamuf. New York: Routledge.

Derrida, J. 1998. Monolingualism of the Other; Or, The Prosthesis of Origin, trans. P. Mensah. Stanford, CA: Stanford University Press.

Derrida, J. 2008. The Animal That Therefore I Am, trans. D. Wills. New York: Fordham University Press.

Foucault, M. 1978. The History of Sexuality, Vol. 1, trans. R. Hurley. New York: Vintage Books.

Foucault, M. 2003. 'Society Must Be Defended': Lectures at the Collège de France, 1975-76, trans. D. Macey, eds. M. Bertani and A. Fontana. New York: Picador Books.

Haraway, D. 2007. When Species Meet. Minneapolis, MN: University of Minnesota Press.

Latour, B. 2007. Reassembling the Social: An Introduction to Actor-Network Theory. Oxford, UK: Oxford University Press.

Lazzarato, M. 2002. From Biopower to Biopolitics. Pli 13: 99-113.

Leroi-Gourhan, A. 1993. Gesture and Speech, trans. A.B. Berger. Cambridge, MA: MIT Press.

Luhmann, N. 1995. Social Systems, trans. J. Bednarz Jr. with D. Baecker. Stanford, CA: Stanford University Press.

Regan, T. 1985. The Case for Animal Rights. Berkeley, CA: University of California Press.

Ritvo, H. 1989. The Animal Estate: The English and Other Creatures in the Victorian Age. Cambridge, MA: Harvard University Press.

Serres, M. 2007. The Parasite, trans. L. Schehr. Minneapolis, MN: University of Minnesota Press.

Singer, P. 1975. Animal Liberation: A New Ethics for Our Treatment of Animals. New York: Avon Books.

Steigler, B. 1998. Technics and Time: The Fault of Epimetheus, trans. R. Beardsworth and G. Collins. Stanford, CA: Stanford University Press.

Wills, D. 1995. Prosthesis. Stanford, CA: Stanford University Press.

Wills, D. 2006. Techneology or the Discourse of Speed. In The Prosthetic Impulse: From a Posthuman Present to a Biocultural Future, eds. M. Smith and J. Morra, 237-264. Cambridge, MA: MIT Press.

Wills, D. 2008. Dorsality: Thinking Back Through Technology and Politics. Minneapolis, $\mathrm{MN}$ : University of Minnesota Press.

Wolfe, C. 2010. What is Posthumanism? Minneapolis, MN: University of Minnesota Press. 